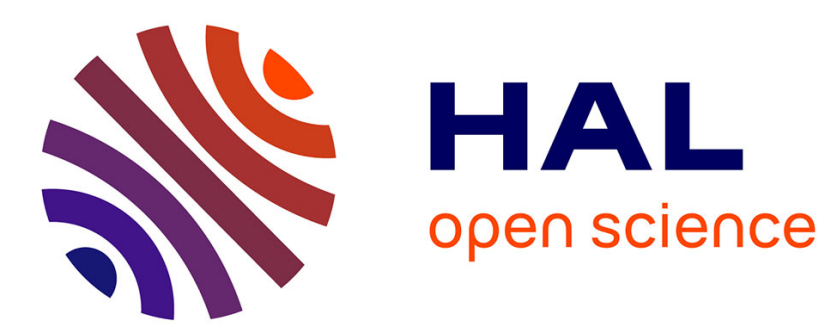

\title{
Structural studies of copper doped 2TeO-PbO-AgO glass by FT-IR and Raman spectroscopies
}

\author{
R. C. Lucacel, I. C. Marcus, I. Ardelean, O. Hulpus
}

\section{To cite this version:}

R. C. Lucacel, I. C. Marcus, I. Ardelean, O. Hulpus. Structural studies of copper doped 2TeO-PbOAgO glass by FT-IR and Raman spectroscopies. European Physical Journal: Applied Physics, 2010, 51 (3), pp.30901. 10.1051/epjap/2010120 . hal-00618498

\section{HAL Id: hal-00618498 https://hal.science/hal-00618498}

Submitted on 2 Sep 2011

HAL is a multi-disciplinary open access archive for the deposit and dissemination of scientific research documents, whether they are published or not. The documents may come from teaching and research institutions in France or abroad, or from public or private research centers.
L'archive ouverte pluridisciplinaire HAL, est destinée au dépôt et à la diffusion de documents scientifiques de niveau recherche, publiés ou non, émanant des établissements d'enseignement et de recherche français ou étrangers, des laboratoires publics ou privés. 


\title{
STRUCTURAL STUDIES OF COPPER DOPED 2TeO $-\mathrm{PbO}$ - $\mathrm{Ag}_{2} \mathrm{O}$ GLASS BY FT-IR AND RAMAN SPECTROSCOPIES
}

\author{
Raluca Ciceo Lucacel ${ }^{1}$, I. C. Marcus ${ }^{2}$, Ioan Ardelean ${ }^{1}$, and Octavia Hulpus ${ }^{1}$ \\ ${ }^{1}$ Faculty of Physics, Babes-Bolyai University, 400084, Cluj-Napoca, Romania, \\ ${ }^{2}$ Institut de Ciencia de Materials de Barcelona, CSIC, Esfera UAB, 08193 Bellaterra, \\ Spain
}

\begin{abstract}
The FT-IR absorption and Raman scattering were used in order to obtain information concerning the short range order in $\mathrm{xCuO} \cdot(100-\mathrm{x})\left[2 \mathrm{TeO}_{2} \cdot \mathrm{PbO} \cdot 0.2 \mathrm{Ag}_{2} \mathrm{O}\right]$ $(0 \leq \mathrm{x} \leq 5 \mathrm{~mol} \%)$ glasses. Moreover, the changes in tellurium atoms coordination that occurs with copper oxide adition were followed. Both techniques reveal that tellurium is disposed in the network structure as trigonal bypiramids $\left(\mathrm{TeO}_{4}\right)$, trigonal pyramids $\left(\mathrm{TeO}_{3}\right)$ along with $\mathrm{TeO}_{3+1}$ polyhedra units. Increasing the $\mathrm{CuO}$ content in the glasses changes the coordination of tellurium atoms from 4 to 3 through the so-called $3+1$ intermediate units, simultaneously with the increase of the non-bridging oxygen (NBOs) causing a depolymerization process in the glass structure.
\end{abstract}

PACS: 61.43.Fs, 78.30.-j

Corresponding author: raluca.lucacel@phys.ubbcluj.ro

Tel: + 40-264-40.53.00, Fax: +40 (264) 591906 


\section{Introduction}

Tellurium oxide glasses are the subject of intense current research because of their interesting electrical and optical properties. $\mathrm{TeO}_{2}$-based multi-component glasses have good glass stability, strength and corrosion resistance [1], high density [2] and low melting temperature $\left(\approx 800^{\circ} \mathrm{C}\right)$ [3]. Tellurite glasses are well known to have the highest refractive index among oxide glasses in the visible and IR region [4] along with a wide band infrared transmittance [5]. Beside these tellurite glasses have also a high dielectric constant [6], high thermal-expansion coefficient [7] and thermochromic properties [2]. Based on the above properties tellurite glasses can be utilized as photonic devices [8], in optical filters, modulators, memories, laser window, in solid state batteries, fuel cells and gas sensors [9].

Different infrared [10,11] and Raman [9, 12-13] spectroscopic studies have showed that tellurite based network is formed from several asymmetric structural units, such as $\mathrm{TeO}_{4}$ trigonal bipyramids (TBP), $\mathrm{TeO}_{3+1}$ polyhedra and $\mathrm{TeO}_{3}$ trigonal pyramids (TP). It is well known that tellurium oxide belongs to the intermediate class of glass-forming oxides and does not readily form glass because the octahedral Te-O polyhedron is highly rapid to get the required distortion of Te-O bonds necessary for forming a stable random network. However, it does form glass when mixed with modifiers such as $\mathrm{PbO}$. Introducing a network modifier into the glass matrix changes the Te coordination polyhedron from $\mathrm{TeO}_{4}$ to $\mathrm{TeO}_{3}$ by breaking Te-O-Te bonds, along with the formation of non-bridging oxygen (NBOs) atoms. It is well know that lead oxide acts in the glass structure as both network modifier and/or former depending upon its concentration in the composition. Beside its interesting behavior lead oxide was chosen also because it gives resistance against devitrification [11]. A recent study has showed that tellurite glasses containing silver nanoparticles posses' optical birefringence [14] and good ionic conductivity [15] while those containing copper oxide present semiconducting and magnetic properties [16].

Therefore, in this work we report the melting synthesis of glasses from $\mathrm{CuO}$ $\mathrm{TeO}_{2}-\mathrm{PbO}-\mathrm{Ag} 2 \mathrm{O}$ system and their structural characterization through spectroscopic methods with a goal to optimize the composition of the glasses for some possible future application. 


\section{Experimental details}

The samples from the $\mathrm{xCuO} \cdot(100-\mathrm{x})\left[2 \mathrm{TeO}_{2} \cdot \mathrm{PbO} \cdot 0.2 \mathrm{Ag}_{2} \mathrm{O}\right]$ where $\mathrm{x}$ values vary from 0 to $5 \mathrm{~mol} \%$ were prepared using the conventional melt quenching technique. The starting materials used were of analytical grade, i.e. $\mathrm{CuO}, \mathrm{TeO}_{2}, \mathrm{PbO}$ and $\mathrm{AgNO}_{3}$. The appropriate amounts of chemicals were manually mixed in an agate pellet. The mixtures corresponding to the desired compositions were melted in air, in sintered corundum crucibles, in an electric furnace at $1150^{\circ} \mathrm{C}$ for 6 minutes. The melts were quickly cooled at room temperature by pouring and stamp them between two stainless-steel plates to avoid any undesired crystallization process. For FT-IR measurements same amount of glasses were powdered and mixed with $\mathrm{KBr}$ in order to obtain thin pellets with a thickness of about $3 \mathrm{~mm}$. The FT-IR absorption spectra were recorded in the range 400-4000 $\mathrm{cm}^{-1}$ with a resolution of $4 \mathrm{~cm}^{-1}$ using an Equinox 55 Bruker spectrometer. The Raman spectra were performed using a Dilor Labram spectrometer (Horiba-Jobin-Yvon, model LabRam) with $785 \mathrm{~nm}$ excitation line from a Spectra Physics model 2016 argon ion laser. The detection of the Raman signal was carried out with a CCD camera (Photometric 9000 model). The spectra were collected in the back-scattering geometry with a resolution of $2 \mathrm{~cm}^{-1}$.

\section{Results and discussion}

The FT-IR spectra obtained for studied glasses are given in figure 1 (a). The spectra were analyzed based on the method given by Condrate and Tarte $[17,18]$ by comparing the experimental data of glasses with those of related crystalline or vitreous compounds. In other words as reference point were used the characteristic absorption bands from vitreous $\mathrm{TeO}_{2}$ and $\mathrm{PbO}$ [19] along with the crystalline compounds $\mathrm{Ag}_{2} \mathrm{O}$ and $\mathrm{CuO}[15,20]$. 


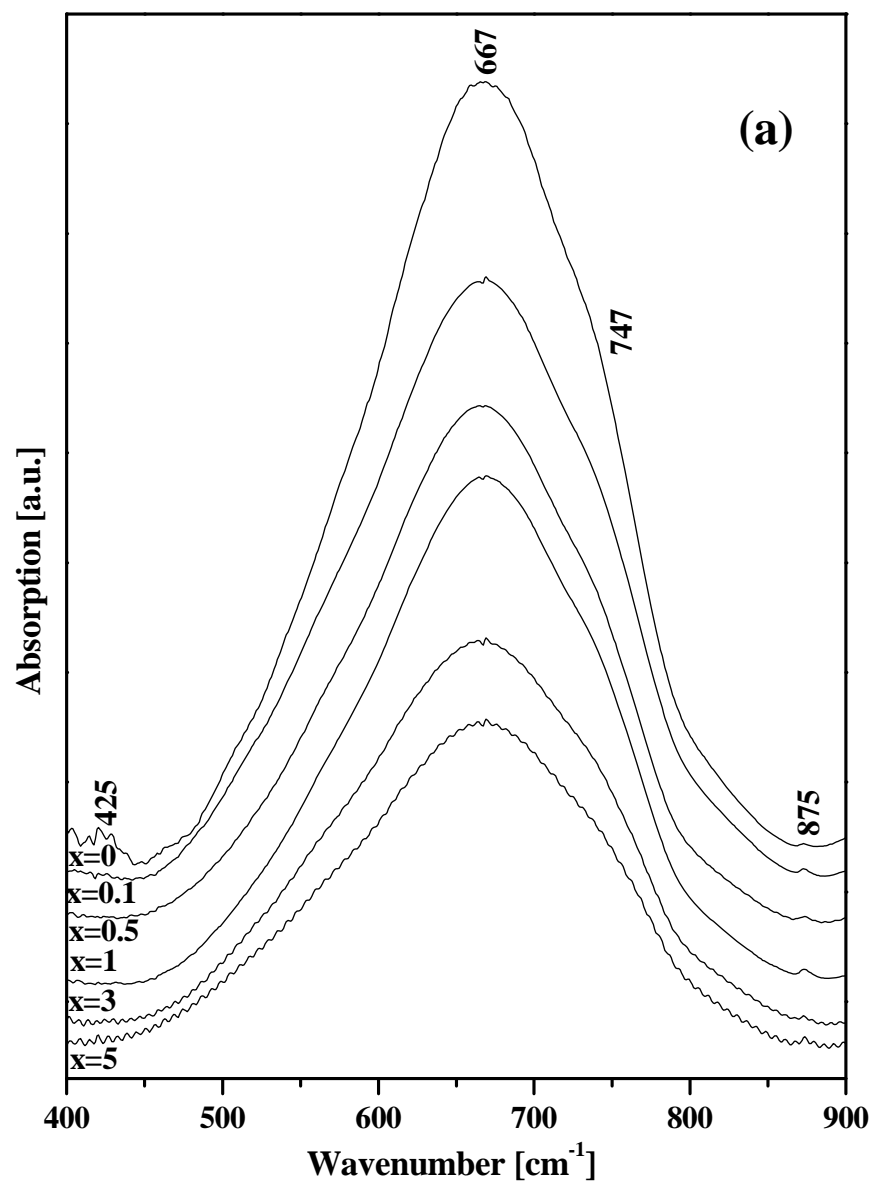

Fig. 1. FT-IR spectra of $\mathrm{xCuO}(100-\mathrm{x})\left[2 \mathrm{TeO}_{2} \cdot \mathrm{PbO} \cdot 0.2 \mathrm{Ag}_{2} \mathrm{O}\right]$ glasses (a)

Due to the fact that the infrared spectra consist on a relatively wide envelope centered at $\sim 667 \mathrm{~cm}^{-1}$, along with minor contribution at $\sim 425$ and $875 \mathrm{~cm}^{-1}$ a curvefitting procedure (PeakFit v4.12) has been use to deconvolute the spectra using the same number of peaks at approximately the same frequency.

The analysis of the deconvoluted spectrum of the glass matrix (figure 1 (b)) shows the existence of four weak bands at $\sim 425, \sim 509, \sim 817$ and $\sim 875 \mathrm{~cm}^{-1}$, two medium bands at $\sim 565$ and $\sim 747 \mathrm{~cm}^{-1}$ and a strong band at $\sim 667 \mathrm{~cm}^{-1}$. Their assignments are summarized in table 1. 


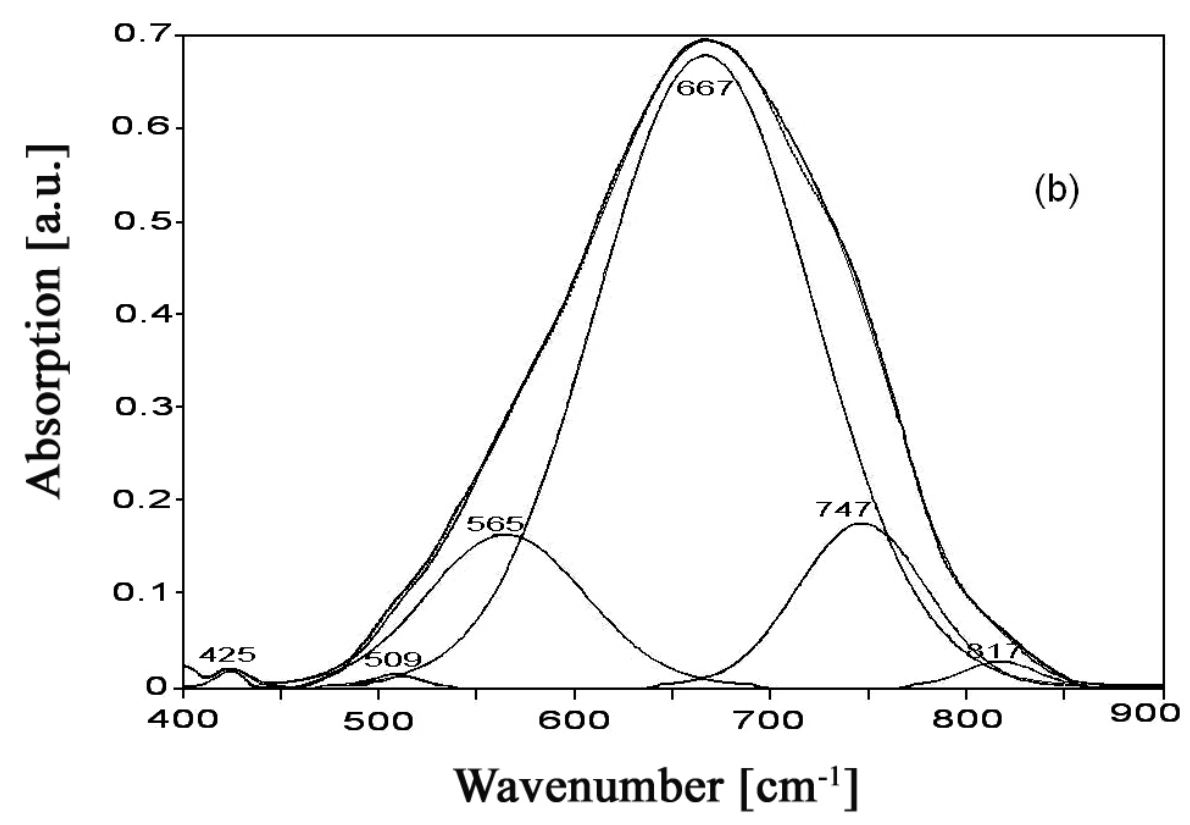

Fig. 1. FT-IR deconvoluted bands of the glass matrix $2 \mathrm{TeO}_{2} \cdot \mathrm{PbO} \cdot 0.2 \mathrm{Ag}_{2} \mathrm{O}$ (b)

Table 1. Assignments of the FT-IR and Raman bands in the spectra of $\mathrm{xCuO}(100-$ $\mathrm{x})\left[2 \mathrm{TeO}_{2} \cdot \mathrm{PbO} \cdot 0.2 \mathrm{Ag}_{2} \mathrm{O}\right]$ glasses

\begin{tabular}{|c|c|c|c|}
\hline \multicolumn{2}{|c|}{$\begin{array}{l}\text { Peak positions } \\
\left(\mathrm{cm}^{-1}\right)\end{array}$} & \multicolumn{2}{|c|}{ Assignments } \\
\hline FT-IR & Raman & FT-IR & Raman \\
\hline & $\sim 335$ & & $\begin{array}{l}\text { Bending vibrations of } \mathrm{TeO}_{3} \text { tp } \\
\text { units with NBOs [24], Te-O-Pb } \\
\text { linkages [12] }\end{array}$ \\
\hline$\sim 425$ & $\sim 465$ & $\begin{array}{l}\text { Vibrations of Te-O-Te bridging } \\
\text { bond in } \mathrm{TeO}_{4} \text { tbp units }[3,10- \\
11,24]\end{array}$ & $\begin{array}{l}\text { Bending vibrations of Te-O-Te } \\
\text { or O-Te-O linkages in } \mathrm{TeO}_{4} \\
\text { tbp units }[9,20]\end{array}$ \\
\hline$\sim 509$ & & $\begin{array}{l}\text { Symmetric Te-O-Te linkage } \\
\text { vibrations [3] }\end{array}$ & \\
\hline$\sim 565$ & & $\begin{array}{l}\text { Te-O vibrations, where the } \mathrm{O} \\
\text { anions were considered as NBO } \\
{[3]}\end{array}$ & \\
\hline$\sim 667$ & $\sim 645$ & $\begin{array}{l}\text { Symmetric stretching vibrations } \\
\text { of Te-O-Te in } \mathrm{TeO}_{4} \text { tbp units }[3 \text {, } \\
11,24]\end{array}$ & $\begin{array}{l}\text { Stretching vibrations of Te-O- } \\
\text { Te linkages from } \mathrm{TeO}_{4} \text { tbp }[2 \text {, } \\
9,24]\end{array}$ \\
\hline
\end{tabular}




\begin{tabular}{|l|l|l|l|}
\hline$\sim 747$ & $\sim 725$ & $\begin{array}{l}\text { Stretching vibrations of } \mathrm{TeO}_{3} \text { tp } \\
\text { or } \mathrm{TeO}_{3+1} \text { polyhedra with } \mathrm{NBOs}^{2} \\
{[11,24]}\end{array}$ & $\begin{array}{l}\text { Stretching vibrations mode of } \\
\mathrm{TeO}_{3+1} \text { polyhedra and } \mathrm{TeO}_{3} \text { tp } \\
\text { with NBOs }[2,9,20,23]\end{array}$ \\
\hline$\sim 817$ & $\begin{array}{l}\text { Stretching vibrations mode of } \\
\mathrm{TeO}_{3} \text { tp with NBOs [3, 13] }\end{array}$ & \\
\hline 875 & & \\
\hline
\end{tabular}

Since we have used in description of these glasses structure the term of TeOn polyhedra, it is necessary to define the terms tbp and the tp units with respect to configuration and bond lengths. Trigonal pyramid units (tp) $\left(\mathrm{TeO}_{3}^{2-}, \mathrm{O}_{2 / 2} \mathrm{Te}-\mathrm{O}\right.$ and $\mathrm{O}_{1 / 2} \mathrm{Te}(=\mathrm{O}) \mathrm{O}^{-}$) have shorter bonds (app. 0.188nm) [21] while $\mathrm{TeO}_{4}$ trigonal bipyramid units (TBP) have longer bonds though the length depends on crystals. Suzuki [22] propose as ones constituent for $\mathrm{TeO}_{2}$ glasses, the $\mathrm{TeO}_{3+1}$ units where three oxygen atoms are at $0.195 \mathrm{~nm}$ and the fourth one at 0.218 nm.

According to the assignments of the infrared absorption bands the glass matrix show that tellurium ions are both $4^{-}$and $3^{-}$coordinated, the network being mainly build by $\mathrm{TeO}_{4}$ (TBP). The existence of the $\mathrm{TeO}_{3}$ trigonal pyramid and $\mathrm{TeO}_{3+1}$ polyhedra unit was also detected in the local structure of vitreous matrix.

Adding gradually small quantities of copper oxide into the glass matrix composition induces some changes in terms of FT-IR line shape. The weak band centered at $\sim 425 \mathrm{~cm}^{-1}$ disappears proving that the Te-O-Te bridging are broken leading to an increase of the amount of the nonbridging oxygen atoms (NBO). Another proof of this aspect is the lack of the band from $\sim 509 \mathrm{~cm}^{-1}$ in the FT-IR spectra of samples containing even and more than $1 \mathrm{~mol} \%$ copper oxide. When the amount of copper oxide reaches the $5 \mathrm{~mol} \%$ value, the band at $\sim 565 \mathrm{~cm}^{-1}$ shifts to a lower wavenumber $\left(\sim 548 \mathrm{~cm}^{-1}\right)$ revealing the increase of the Te-O- bond and more over, the gradually depolimerisation of the glass network.

The absorption band centered at $\sim 667 \mathrm{~cm}^{-1}$ dominates the spectra through all compositional range showing the predominance of $\mathrm{TeO}_{4}$ tbp units in the local 
structure of these glasses. On the other hand no major changes undergo with the bands from $\sim 747, \sim 817$ and $\sim 875 \mathrm{~cm}^{-1}$ with the copper oxide addition.

Based on the way in which the infrared spectra of these glasses has changed at the copper oxide addition we may assume a minor rearrangement tendency of the local structure which relates mostly to changes in the relative amount of $\mathrm{TeO}_{3}$ and $\mathrm{TeO}_{4}$ units. A better understanding of the changes that occur in the local order of these glasses can be obtained by calculating the relative area under the infrared absorption bands that are responsible for $v\left(\mathrm{TeO}_{3}\right)$ and $v\left(\mathrm{TeO}_{4}\right)$, keeping in view that the main contributions of those appear around $747,817,875 \mathrm{~cm}^{-1}$ for $\mathrm{TeO}_{3}$ units and 425, $667 \mathrm{~cm}^{-1}$ for $\mathrm{TeO}_{4}$ units. So that, we have calculated the relative areas corresponding to these peaks individually, then we have found the relative area corresponding to the peaks coming from all $\mathrm{TeO}_{3}$ units $\left(\mathrm{A}_{\mathrm{TeO}_{3}}\right)$ and all $\mathrm{TeO}_{4}$ units $\left(\mathrm{A}_{\mathrm{TeO}_{4}}\right)$. We assume that the calculated ratio between these two geometrical relative areas $\left(\mathrm{A}_{\mathrm{r}}=\mathrm{A}_{\mathrm{TeO}_{3}} / \mathrm{A}_{\mathrm{TeO}_{4}}\right)$ reflect the ration between the relative amount of $\mathrm{TeO}_{3}$ $\left(\mathrm{N}_{\mathrm{TeO}_{3}}\right)$ and $\mathrm{TeO}_{4}\left(\mathrm{~N}_{\mathrm{TeO}_{4}}\right)$ units $\left(\mathrm{A}_{\mathrm{r}} \sim \mathrm{N}_{\mathrm{TeO}_{3}} / \mathrm{N}_{\mathrm{TeO}_{4}}\right)$. The evolution of the ratio between the relative amount of $\mathrm{TeO}_{3}$ and $\mathrm{TeO}_{4}$ units $\mathrm{A}_{\mathrm{r}}$ as function of copper oxide $\mathrm{mol} \%$ concentration is shown in figure 2 (a).

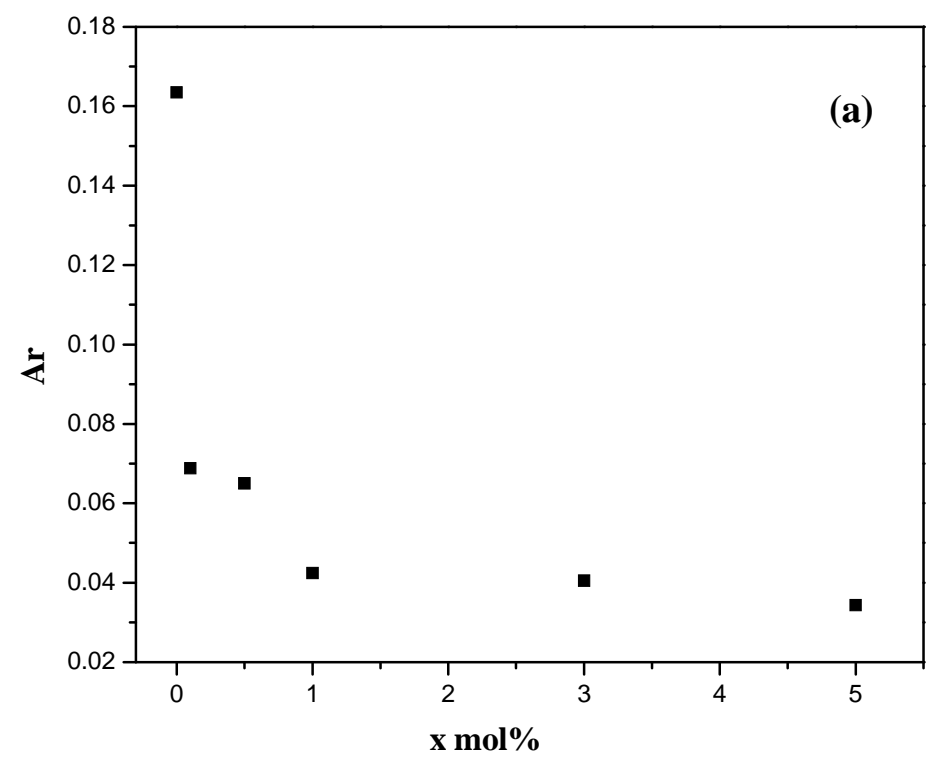

Fig. 2. Ar ratio vs. $\mathrm{x} \mathrm{mol} \%$ (a) 
All the values of $A_{r}$ ratio are powerfully sub unitary signifying as we suspect that in all compositional range the amount of the units where tellurium is $4^{-}$ coordinated is higher than the one in which is $3^{-}$coordinated. The trend of $A_{r}$ ratio with the copper oxide confirms the gradual depolymerization of the vitreous network at $\mathrm{CuO}$ addition. The transition between $\mathrm{TeO}_{4}$ and $\mathrm{TeO}_{3}$ structural units is made by shortening of one of the axial bond while one equatorial bond gets longer $\left(\mathrm{TeO}_{3+1}\right.$ polyhedra).

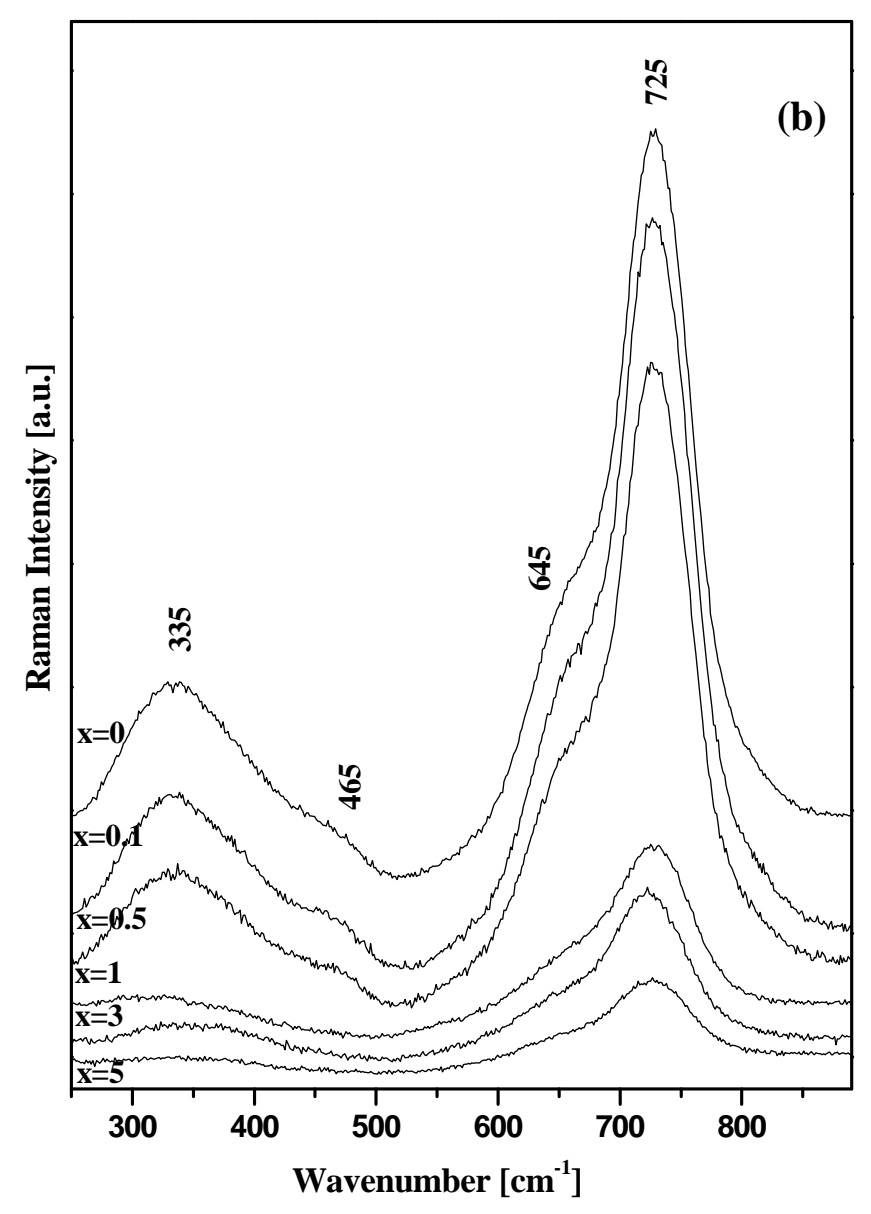

Fig. 2. Raman spectra of $\mathrm{xCuO}(100-\mathrm{x})\left[2 \mathrm{TeO} \mathrm{O}_{2} \cdot \mathrm{PbO} \cdot 0.2 \mathrm{Ag}_{2} \mathrm{O}\right]$ glasses $(\mathrm{b})$

Figure 2 (b) shows the Raman spectra of the investigated glasses. The assignments of the bands detected in the Raman spectra are also listed in table 1. Raman spectrum of the glass matrix is dominated by two bands centered at $\sim 335 \mathrm{~cm}^{-1}$ 
and $\sim 725 \mathrm{~cm}^{-1}$. Raman measurements seem to be more sensitive to the direct effect of the lead oxide as modifier into the glass matrix network rather than the infrared measurements. Noticeable effects are as follows: first the appearance of the band at $335 \mathrm{~cm}^{-1}$ which can be either assigned to the bending vibrations of $\mathrm{TeO}_{3}$ tp units with NBOs or to the Te-O-Pb bond and second the fact that the band from $725 \mathrm{~cm}^{-1}$ (responsible for vibrations mode of $\mathrm{TeO}_{3+1}$ polyhedra and $\mathrm{TeO}_{3}$ tp with NBOs) it is already present - usually it appears when the network is already depolimerised. This happens because $\mathrm{PbO}$ enters into the glass lattice network by breaking up the Te-O-Te bonds (the oxygen atoms of lead oxide beak the local symmetry while $\mathrm{Pb}^{2+}$ ions occupy interstitial positions) inducing coordinated rearrangements. Along these two above bands, Raman spectrum of the matrix presents also two shoulders centered at $\sim 465 \mathrm{~cm}^{-1}$ and $\sim 645 \mathrm{~cm}^{-1}$ proving the existence of the three structural units detected also through the FT-IR measurements is confirmed by the Raman scattering. Therefore, the structure of the glass matrix network is a mixture of $\mathrm{TeO}_{4}, \mathrm{TeO}_{3+1}$ and $\mathrm{TeO}_{3}$ units. A very confusing aspect is regarding to the fact that the Raman spectra present a dominant band centered at $\sim 725 \mathrm{~cm}^{-1}$ revealing a structure mainly build by $\mathrm{TeO}_{3+1}$ and trigonal pyramid units-contrary with that proposed by FT-IR data. So that, we assume that the contribution of TP units at this band is minor related to that of $\mathrm{TeO}_{3+1}$ units.

With copper oxide addition the Raman intensity of all bands decreases slowly up to $0.5 \mathrm{~mol} \%$ and then rapidly for the rest of compositional domain. This evolution indicates that the change in coordination of Te atoms depends strongly on the cation. Thus, while the band from $645 \mathrm{~cm}^{-1}$ is exclusively due to the $\mathrm{TeO}_{4}$ units and band from $725 \mathrm{~cm}^{-1}$ is due to both $\mathrm{TeO}_{3}$ and $\mathrm{TeO}_{4}$ it is quite difficult to predict the exact amount of each TBP and TP units. Still it is obvious that copper oxide addition induces a continuously depolimerisation of these glasses local structure given by the increases of TP units and probably NBO atoms numbers. 


\section{Conclusion}

The glasses from $\mathrm{xCuO} \cdot(100-\mathrm{x})\left[2 \mathrm{TeO}_{2} \cdot \mathrm{PbO} \cdot 0.2 \mathrm{Ag}_{2} \mathrm{O}\right](0 \leq \mathrm{x} \leq 5 \mathrm{~mol} \%)$ system were prepared and investigated through FT-IR absorption and Raman scattering. The presence of the $\mathrm{TeO}_{4}, \mathrm{TeO}_{3+1}$ and $\mathrm{TeO}_{3}$ structural units in these glasses local structure was detected by both techniques used. Moreover, we assume that $\mathrm{TeO}_{4}$ and $\mathrm{TeO}_{3+1}$ structural units dominate the vitreous network of these samples. A gradually depolymerization of the glass network with $\mathrm{CuO}$ addition was evidenced. The increase of the disorder at short range order is given by the transformation of $\mathrm{TeO}_{4}$ and $\mathrm{TeO}_{3+1}$ units to $\mathrm{TeO}_{3}$ ones along with the increase of $\mathrm{NBO}$ atoms number. All these sustained that the $\mathrm{CuO}$ behaves as a network modifying oxide in these tellurite based glasses. 


\section{References}

1. O’Donnell, M. D., Miller, C. A., Furniss, D., Tikhomirov, V. K. \& Seddon, A. B. J. Non-Cryst. Solids 331, 48 (2003)

2. Udovic, M., Thomas, P., Mirgorodsky, A., Durand, O., Soulis, M., Masson, O., Merle-Mejean, T. \& Champarnaud-Mesjard, J. C. J. Solid State Chem. 179, 3252 (2006)

3. Abd El-Moneim, A. Mat. Chem. Phys. 73, 318 (2002)

4. Wang, C. Y., Shen, Z. X. \& Chowdari, B. V. R. J. Raman Spectrosc. 29, 819 (1988)

5. Himei, Y., Miura, Y., Nanba, T. \& Osaka, A. J. Non-Cryst. Solids 211, 64 (1997)

6. Abd El-Moneim, A. Physica B: Condensed matter 334, 234 (2003)

7. Sabadel, J. C., Armand, P., Cachau-Herreillat, D., Baldeck, P., Doclot, O., Ibanez, A. \& Philippot, E. J. Solid State Chem. 132, 411 (1997)

8. Amorim, H. T., Vermelho, M. V. D., Gouveia-Neto, A. S., Cassanjes, F. C., Ribeiro, S. J. L., Messaddeq, Y., \& Messaddeq, Y. J. of Alloys Comp. 346, 282 (2002)

9. Duverger, C., Bouazaoui, M. \& Turrell, S. J. Non-Cryst. Solids 220, 169 (1997)

10. Baia, L., Bolboaca, M., Kiefer, W., Yousef, E. S., Rüssel, C., Breitbarth, F. W., Mayerhöfer, T. G. \& Popp, J. Phys. Chem. Glasses 45 (3), 178 (2004)

11. Ravi Kumar V. \& Veeraiah, N. J. Mat. Sci. Lett. 16, 1816 (1997)

12. Silva, M. A. P., Messaddeq, Y., Ribeiro, S. J. L., Poulain, M., Villain, F. \& Briois, V. J. Phys. Chem. Solids 62, 1055 (2001)

13. Ciceo Lucacel, R. \& Ardelean, I. Phys. Chem. Glasses 45 (4), 295 (2004) 
14. Murai, S., Hattori, R., Fujita, K,. \& Tanaka, K. Applied Physics Express 2 (10), $102001(2009)$

15. Chowdari, B. V. R., Tan, K. L. \& Ling Fang, J. Mat. Sci. 35, 2015 (2000)

16. Khattak, G. D., Mekki, A. \& Wegner, L. E. J. Non-Cryst. Solids 337, 174 (2004)

17. Tarte, P., Physics of Non Crystalline Solids, Ed. I. A. Prins, Elsevier, Amsterdam, 1964, p.549

18. Condrate, R. A., Introduction to glass science, Ed. L. D. Pye, H. J. Stevens and W.C. Lacourse, Plenum Press, New York, 1972, p. 101-135.

19. Duverger, C., Bouazaoui, M. \& Turrell, S. J. Non-Cryst. Solids 220, 169 (1997)

20. Iwadate, Y., Suzuki, M., Hattori, T., Fukushima, K., Nishiyama, S., Misawa, M., Fukunaga, T. \& Itoh, K. J. Alloys and Compounds 389, 229 (2005)

21. Rong, Q. J., Osaka, A., Nanba, T., Takada, J., \& Miura, Y. J. Mat. Sci. 27, 3793 (1992)

22. Suzuki, K. J. Non-Cryst. Solids 95/96, 15 (1987)

23. Jaba, N., Mermet, A., Duval, E. \& Champagnon B., J. Non-Cryst. Solids 351, 833 (2005)

24. Sabadel, J. C., Armand, P., Lippens, P. E., Cachau-Herreillat, D. \& Philip, E. J. Non-Cryst. Solids 244, 143 (1999) 